\title{
Seroprevalence of anti-hepatitis E virus antibodies in domestic pigs in Mexico
}

\author{
Montserrat Elemi García-Hernández', Mayra Cruz-Rivera², José Iván Sánchez-Betancourt', Oscar Rico-Chávez', \\ Arely Vergara-Castañeda ${ }^{3}$, María E. Trujillo ${ }^{1}$ and Rosa Elena Sarmiento-Silva ${ }^{1 *}$
}

\begin{abstract}
Background: Hepatitis E virus (HEV) infection is one of the most common causes of acute liver diseases in humans worldwide. In developing countries, HEV is commonly associated with waterborne outbreaks. Conversely, in industrialized countries, HEV infection is often associated with travel to endemic regions or ingestion of contaminated animal products. Limited information on both, human and animal HEV infection in Mexico is available. As a consequence, the distribution of the virus in the country is largely unknown. Here, we assessed the seroprevalence of HEV among swine in different geographical regions in Mexico.
\end{abstract}

Methods: Seroprevalence of anti-HEV antibodies in swine herds in Mexico was evaluated in a representative sample including 945 pig serum specimens from different regions of the country using a commercial enzyme-linked immunosorbent assay (ELISA).

Results: The overall prevalence of anti-HEV antibodies in swine was $59.4 \%$. The northern region of Mexico exhibited the highest seroprevalence in the country (86.6\%), while the central and southern regions in Mexico showed lower seroprevalence, $42.7 \%$ and $51.5 \%$, respectively.

Conclusions: In Mexico, HEV seroprevalence in swine is high. Importantly, northern Mexico showed the highest seroprevalence in the country. Thus, further studies are required to identify the risk factors contributing to HEV transmission among pigs in the country. Assessment of HEV human infection in the context of viral transmission in swine is required to better understand the epidemiology of hepatitis $\mathrm{E}$ in Mexico.

Keywords: HEV, Mexico, Pigs, Seroprevalence

\section{Background}

Hepatitis E virus (HEV) infection is an emerging disease of increasing importance. HEV affects approximately $\sim 20$ million persons annually worldwide, causing $\sim 70,000$ deaths. In humans, HEV is transmitted primarily by the fecal-oral route $[1,2]$. Clinically, hepatitis $\mathrm{E}$ is indistinguishable from other viral hepatitis. Hepatitis $\mathrm{E}$ is usually a self-limiting disease in immunocompetent individuals, commonly resulting in mild symptoms or asymptomatic disease [3-6]. Occasionally, and for reasons not completely understood, HEV infection can progress to fulminant hepatitis [7]. The overall mortality rate of HEV

\footnotetext{
* Correspondence: rosass@unam.mx

${ }^{1}$ Facultad de Medicina Veterinaria y Zootecnia, Universidad Nacional

Autónoma de México, Ciudad de México 04510, México

Full list of author information is available at the end of the article
}

infection ranges from 0.5 to $4 \%$; however, it is considerably higher among pregnant women ( 20\%) [2].

HEV is a non-enveloped virus with a single-stranded positive-sense RNA genome of ca. $7.2(\mathrm{~kb})$ in length. $\mathrm{HEV}$ is a member of the family Hepeviridae within the genus Orthohepevirus. This genus comprises four species: Orthohepevirus A, Orthohepevirus B, Orthohepevirus $C$ and Orthohepevirus $D$-all grouping viruses that infect birds and different mammals. Based on its genetic variability, Orthohepevirus $A$ is classified into seven main genotypes (HEV1-7). Genotypes 1 and 2 infect exclusively humans while all other are considered zoonotic. Genotypes 3 and 4 also affect pigs, wild boars, rabbits and mongoose. Genotype 5 and 6 have been identified from wild boar, while genotype 7 infects camels. 
HEV is endemic or epidemic to Africa and Asia. Epidemics of HEV in endemic regions are usually associated with water-borne outbreaks [1, 8]. Individuals from non-endemic regions who acquire HEV infection often have a history of traveling to endemic regions and/or consumption of contaminated animal products [9] evidence suggests that autochthonous HEV infections in developed countries also occur [7, 10]. HEV has been reported to circulate in different countries in Latin America, including Mexico [11]. After the first reported HEV outbreak in Mexico in 1987 [12], when HEV genotype 2 was originally described, several research groups have subsequently reported the circulation of HEV in the country in both, swine and humans $[2,13,14]$. In Mexico, HEV surveillance is not routinely performed; and as a result, diagnosis of HEVrelated disease is underreported. Likewise, monitoring of HEV infection in pigs is rare [15]. Thus resulting in a profound lack of information about human and animal infection.

In pigs, reduced feed intake and mild diarrhea may be observed, but evident clinical disease signs such as elevation of liver enzymes or bilirubin levels are usually not detected. Upon infection, experimentally HEVinoculated pigs seroconvert to anti-HEV immunoglobulin IgG, shedding of virus in feces is observed during approximately 23 days in contact infected pigs [16, 17]. Importantly, identification of HEV RNA in liver tissue and bile is not uncommon [18]. Higher anti-HEV antibody prevalence among individuals in close contact with pigs (handlers), in comparison to normal population has been previously reported [19]. In these settings, HEVrelated disease has been related to consumption of contaminated meat products.

In this study we aimed to assess the seroprevalence of HEV in domesticated pigs in different geographical regions in Mexico.

\section{Methods}

\section{Serum samples}

Serum samples were obtained from different farms in 2014 and 2015 with informed consent from the owners. A total of 945 representative swine serum samples were selected for this study. Both, industrialized farms (95\%) and backyard herds (5\%) located in different counties from 27 states in Mexico were included. Samples were grouped according to their collection site and divided into three geographical regions (central, southern and northern Mexico) (Fig. 1). The sample size for statistical significant result for each region was calculated using the Daniel algorithm [20].

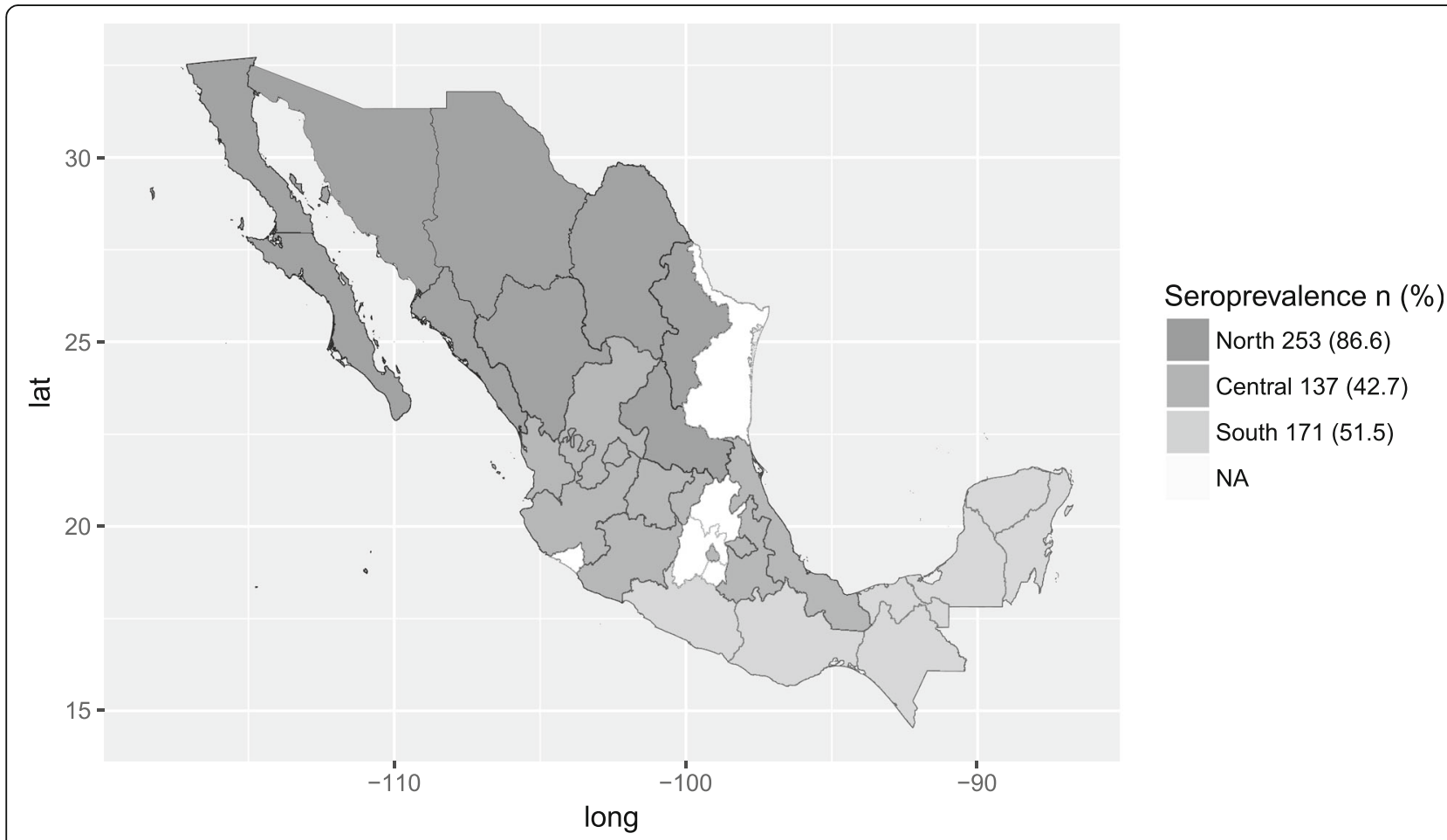

Fig. 1 Map showing the percentage of anti-HEV positive pigs and classification by region of the states included in the study. The central region included samples from Ciudad de Mexico, Guanajuato, Jalisco, Michoacán, Nayarit, Puebla, Queretaro, Aguascalientes, Tlaxcala, Veracruz and Zacatecas states, south from Quintana Roo, Campeche, Chiapas, Guerrero, Oaxaca, Tabasco and Yucatan; and northern states Baja California, Chihuahua, Coahuila, Durango, Nuevo Leon, Sinaloa, San Luis Potosi and Sonora. Latitude (Long). Latitude (lat). NA (Not available) 


\section{Detection of anti-HEV antibodies}

Detection of anti-HEV antibodies was performed using a commercial enzyme-linked immunosorbent assay (ELISA) (Wantai Biopharmaceutical, Inc. Beijing, China), using horseradish peroxidase-labeled protein A (Bio-Rad, CA, USA) as reporting conjugate. Briefly, serum samples were diluted (1:10), and incubated for $30 \mathrm{~min}$ at $37{ }^{\circ} \mathrm{C}$. After washing, the conjugate was added and incubated for $30 \mathrm{~min}$ at $37{ }^{\circ} \mathrm{C}$. Plates were washed, and $100 \mu \mathrm{l}$ of substrate solution (tetramethylbenzidine, Wantai Biopharmaceutical) were added. The reaction was stopped after $15 \mathrm{~min}$ with $50 \mu \mathrm{l}$ of stop solution. The absorbance was measured at $450 \mathrm{~nm}$ using multi-scan EX spectrophotometer (Thermo Fisher, Waltham, MA). The cut off value was calculated after blanking as the mean absorbance of the negative controls +0.16 (mean absorbance value for negative controls +0.16 ) according to the manufacturer's instructions. Serum specimens exhibiting an absorbance value greater than the cut-off value were considered positive for anti-HEV antibodies.

\section{Statistical analyses}

Statistical analyses were performed using the Statistical Package for the Social Sciences (IBM SPSS Statistics v22.0, USA). All reported $p$-values were two-sided and a p-value of less than 0.05 was deemed statistically significant. Prevalence of positive serum among swine categories and regions were assessed by the chi- squared test and odds ratios were determined to evaluate the risk of positive/negative results for qualitative results, according to location and production stage.

In order to know the effect of each state in the corresponding region in the hepatitis seroprevalence we performed a general linear model (glm) with binomial distribution. The positive or negative result of hepatitis seroprevalence was used as dependent variable, while the region, state within region and production stage within region were used as independent variables. These analysis were performed selected the states with at least 10 observations, after the selection the sample size was equal to 878. A likelihood test was performed to determine the overall significance of the logistic model. The odd ratio of each state and region was calculated by exponentiating the model estimates. An analysis of variance was also calculated to know the statistically difference in hepatitis seroprevalence by state.

\section{Results}

A total of 945 samples were analyzed, 292 (30.8\%) specimens were collected from the northern region of Mexico, and 332 sera from the southern (35.1\%) and 321 central parts of Mexico (34\%) and, when classified according to the production stage, a total of 299 samples corresponded to weaned production, 323 to fattening and 323 to reproducers animals (Table 1 ). No differences in distribution for this factor were found among the total of the samples.

The overall prevalence of anti-HEV IgG in the country was $59.4 \%$. The highest seroprevalence was found in northern Mexico (86.6\%), compared to 42.7 and $51.5 \%$ in the central and southern regions, respectively $(p<0.001)$ (Fig. 1). Based on the production stage, the chi- squared test showed no significant differences in positivity between the different production stages in the northern and central regions; however, in southern Mexico, a significant difference was observed in fattening swine compared to weaned and reproducer animals $(p=0.012)$.

In the general linear model (glm) with binomial distribution, only the states with at least 10 observations were selected $(n=878)$, in this analysis, the production stage within region didn't show a statistical significance (LR chisq $=9.755, \mathrm{DF}=6, p=0.135)(\mathrm{AIC}=948.84)$ while the state within region showed a statistical significance $(\mathrm{LR}$ chisq $=115.56, \mathrm{DF}=13 p<0.01)(\mathrm{AIC}=946.6)$. The central region was used as intercept in the glm (Table 2). No significant difference was found in the analysis of variance in hepatitis seroprevalence by state $(\mathrm{DF}=2, \mathrm{~F}=2.59, p=0.118)$.

\section{Discussion}

Here, we have shown a high prevalence of HEV-specific antibodies in domesticated pigs in different geographical regions of Mexico. The results suggested that animals in intensive pig farms are in contact with HEV at an early production stage. Few studies have reported the circulation of HEV in Mexico, particularly in pigs [15]. As a consequence, limited information about the seroprevalence of $\mathrm{HEV}$ in swine is available. A recent study, conducted in nine states located in central Mexico showed a seroprevalence of $30 \%$ [15]. The discrepancies between the seroprevalence found between the studies can be attributed to the difference in geographical areas tested and the methodology used by Merino-Ramos and cols which consisted of an ELISA test based on the use of recombinant HEV 3 ORF-2 expressed in Trichoplusia ni larvae as antigen. Performances of anti-HEV antibody detection methods vary significantly [21]. Here, we used a well-known commercial assay for the detection of antibodies in order to minimize

Table 1 Classification of analyzed samples by region and production stage

\begin{tabular}{lllll}
\hline Category & Total & North & South & Central \\
\hline Weaned & $299(31.6)$ & $88(29.4)$ & $115(38.4)$ & $96(32.1)$ \\
Fattening & $323(34.2)$ & $94(29.1)$ & $116(35.9)$ & $113(35)$ \\
Reproducers & $323(34.2)$ & $110(34)$ & $101(31.3)$ & $112(34.7)$ \\
& & $292(30.8)$ & $332(35.1)$ & $321(34)$ \\
\hline
\end{tabular}

Data shown as $\mathrm{n}(\%)$ 
Table 2 Out put of general lineal model. The region and the state within region were used as independent variables. Only states with $>10$ observations were considered

\begin{tabular}{|c|c|c|c|c|c|c|c|c|c|c|}
\hline Region & State & Estimate & Std. Error & $z$ value & $P$ & $\mathrm{~N}$ & Prevalence (\%) & OR & $2.50 \%$ & $97.50 \%$ \\
\hline \multirow[t]{7}{*}{ Center (intercept) } & & 0.588 & 0.558 & 1.054 & 0.292 & 299 & 44.1 & 1 & & \\
\hline & DF & -0.728 & 0.636 & -1.144 & 0.253 & 43 & 46.5 & 0.483 & 0.13 & 1.637 \\
\hline & Guanajuato & -0.007 & 0.599 & -0.011 & 0.991 & 92 & 64.1 & 0.993 & 0.285 & 3.127 \\
\hline & Jalisco & -1.314 & 0.6 & -2.188 & $0.029^{*}$ & 92 & 32.6 & 0.269 & 0.077 & 0.847 \\
\hline & Michoacan & -2.821 & 0.825 & -3.421 & $0.001^{*}$ & 31 & 9.7 & 0.06 & 0.01 & 0.271 \\
\hline & Queretaro & -0.588 & 0.843 & -0.697 & 0.486 & 10 & 50.0 & 0.556 & 0.101 & 2.905 \\
\hline & Veracruz & -1.194 & 0.754 & -1.583 & 0.113 & 17 & 35.3 & 0.303 & 0.064 & 1.282 \\
\hline \multirow[t]{3}{*}{ North } & & 2.105 & 0.627 & 3.356 & $0.001^{*}$ & 256 & 89.5 & 8.205 & 2.258 & 27.636 \\
\hline & Nuevo Leon & -1.083 & 0.618 & -1.752 & 0.08 & 24 & 83.3 & 0.339 & 0.108 & 1.288 \\
\hline & Sinaloa & -2.162 & 0.491 & -4.404 & $0.000^{*}$ & 27 & 63.0 & 0.115 & 0.044 & 0.305 \\
\hline \multirow[t]{6}{*}{ South } & & 1.284 & 0.774 & 1.658 & 0.097 & 323 & 52.0 & 3.611 & 0.794 & 17.653 \\
\hline & Chiapas & -3.163 & 0.636 & -4.974 & $0.000^{*}$ & 51 & 21.6 & 0.042 & 0.011 & 0.134 \\
\hline & Guerrero & -1.664 & 0.654 & -2.544 & $0.011^{*}$ & 29 & 55.2 & 0.189 & 0.047 & 0.638 \\
\hline & Oaxaca & -0.599 & 0.687 & -0.872 & 0.383 & 32 & 78.1 & 0.549 & 0.13 & 2.051 \\
\hline & Tabasco & -4.27 & 1.174 & -3.635 & $0.000^{*}$ & 12 & 8.3 & 0.014 & 0.001 & 0.098 \\
\hline & Yucatan & -1.765 & 0.559 & -3.159 & $0.002^{*}$ & 169 & 52.7 & 0.171 & 0.049 & 0.463 \\
\hline
\end{tabular}

Odds ratio $(\mathrm{OR})$

GLM

${ }^{*} p<0.05$

false antibody results [22-28]. Interestingly, HEV seroprevalence in pig herds in Mexico has been reported as high as $81 \%$ [2]. Both previous studies were focused in particular geographical regions in Mexico. Here, we undertook a nation-wide approach to assess the HEV seroprevalence in swine in the country, showing that northern Mexico is the most affected region by HEV infection in pigs. Nonetheless, high seroprevalence in all three geographical regions was observed. The reasons for these differences in seropositivity among different parts of Mexico could be associated with common practices in pig farms such as high population density, and shorter production cycles that significantly increased the risk for HEV infection [16].

Studies aimed to detect the virus in acutely infected animals are necessary to identify the routes of transmission exploited by the virus to warrant persistence in the pig population.

\section{Conclusions}

The relatively high seropositivity observed in all regions in Mexico suggests abundant circulation of HEV and high transmission rates among pigs. These findings highlight the importance of this zoonosis in Mexico. Further nation-wide studies on HEV prevalence in human population are required to better understand the epidemiology of HEV in Mexico. Assessing the prevalence of HEV infection in high-risk populations such as pig handlers and immunocompromised patients is critical to estimate HEV burden in the country. Implementation of adequate HEV surveillance in Mexico is important to implement proper control measures aimed to prevent virus spread.

\section{Abbreviations \\ Cl: Confidence interval; ELISA: Competitive enzyme-linked immunosorbent assay; HEV: Hepatitis E virus; OR: Odds ratio}

\section{Acknowledgements}

MEGH and the founding for the project (CB221186) was supported by the Mexican National Council of Science and Technology (CONACYT). The authors would like to thank Jose Juan Martínez for critical reading of the manuscript.

Availability of data and materials

The data supporting these research findings are included within the article.

\section{Authors' contributions}

Performed experiments and analyzed the data: MEGH, MCR, AVC, RESS. Wrote the manuscript: MEGH, MCR, AVC, RESS. Collected sample material and supported data analysis: MEGH, JISB, MET, RESS. Supervised and supported the study: RESS. All authors read and approved the final manuscript.

\section{Ethics approval and consent to participate}

Samples were selected from serum specimen resources originally obtained for the purpose of porcine reproductive and respiratory syndrome virus (PRRSV) surveillance with the approval of state producers committees. Sample collection took place in 2014 and 2015 by local veterinary physicians.

\section{Competing interests}

The authors declare that they have no competing interests.

\section{Publisher's Note}

Springer Nature remains neutral with regard to jurisdictional claims in published maps and institutional affiliations.

\section{Author details}

${ }^{1}$ Facultad de Medicina Veterinaria y Zootecnia, Universidad Nacional Autónoma de México, Ciudad de México 04510, México. ${ }^{2}$ Facultad de 
Medicina, Universidad Nacional Autónoma de México, 04510 Ciudad de México, México. ${ }^{3}$ Facultad de Ciencias Químicas, Universidad La Salle, Benjamín Franklin 47, 06140 Ciudad de México, México.

Received: 14 June 2016 Accepted: 14 September 2017

Published online: 21 September 2017

\section{References}

1. Krawczynski K, Mast EE, Purdy MA. Hepatitis E: an overview. Minerva Gastroenterol Dietol. 1999;45(2):119-30. discussion 130-115

2. Cooper K, Huang FF, Batista L, Rayo CD, Bezanilla JC, Toth TE, Meng XJ. Identification of genotype 3 hepatitis $E$ virus (HEV) in serum and fecal samples from pigs in Thailand and Mexico, where genotype 1 and $2 \mathrm{HEV}$ strains are prevalent in the respective human populations. J Clin Microbiol. 2005:43(4):1684-8

3. Aggarwal A, Perumpail RB, Tummala S, Ahmed A. Hepatitis E virus infection in the liver transplant recipients: clinical presentation and management. World J Hepatol. 2016;8(2):117-22.

4. Aggarwal R. Clinical presentation of hepatitis E. Virus Res. 2011;161(1):15-22.

5. Aggarwal R. Hepatitis E: clinical presentation in disease-endemic areas and diagnosis. Semin Liver Dis. 2013;33(1):30-40.

6. Aggarwal R, Krawczynski K. Hepatitis E: an overview and recent advances in clinical and laboratory research. J Gastroenterol Hepatol. 2000;15(1):9-20.

7. Festa S, Garbuglia AR, Baccini F, Panzuto F, Capobianchi MR, Santino I, Purchiaroni F, Orgera G, Delle Fave G, Marignani M. Acute fulminant hepatitis $E$ virus genotype $3 e$ infection: description of the first case in Europe. Scand J Infect Dis. 2014;46(10):727-31.

8. Guthmann JP, Klovstad H, Boccia D, Hamid N, Pinoges L, Nizou JY, Tatay M, Diaz F, Moren A, Grais RF, et al. A large outbreak of hepatitis E among a displaced population in Darfur, Sudan, 2004: the role of water treatment methods. Clin Infectious Dis. 2006;42(12):1685-91.

9. Berto A, Martelli F, Grierson S, Banks M. Hepatitis E virus in pork food chain, United Kingdom, 2009-2010. Emerg Infect Dis. 2012;18(8):1358-60

10. Schielke A, Sachs K, Lierz M, Appel B, Jansen A, Johne R. Detection of hepatitis $E$ virus in wild boars of rural and urban regions in Germany and whole genome characterization of an endemic strain. Virol J. 2009;6:58.

11. Fierro NA, Realpe M, Meraz-Medina T, Roman S, Panduro A. Hepatitis E virus: an ancient hidden enemy in Latin America. World J Gastroenterol. 2016;22(7):2271-83

12. Velazquez O, Stetler HC, Avila C, Ornelas G, Alvarez C, Hadler SC, Bradley DW, Sepulveda J. Epidemic transmission of enterically transmitted non-a, non-B hepatitis in Mexico, 1986-1987. JAMA. 1990;263(24):3281-5.

13. Alvarez-Munoz MT, Torres J, Damasio L, Gomez A, Tapia-Conyer R, Munoz O. Seroepidemiology of hepatitis E virus infection in Mexican subjects 1 to 29 years of age. Arch Med Res. 1999;30(3):251-4.

14. Bernal Reyes R. Licona Solis JE: [Seroepidemiology of hepatitis $E$ in the state of hidalgo]. Revista de Gastroenterol de Mexico. 1996;61(3):233-8.

15. Merino-Ramos T, Martin-Acebes MA, Casal J, Saiz JC, Loza-Rubio E. Prevalence of hepatitis E virus (HEV) antibodies in Mexican pigs. Food Environ Virol. 2016;

16. Walachowski S, Dorenlor V, Lefevre J, Lunazzi A, Eono F, Merbah T, Eveno E, Pavio N, Rose N. Risk factors associated with the presence of hepatitis $\mathrm{E}$ virus in livers and seroprevalence in slaughter-age pigs: a retrospective study of 90 swine farms in France. Epidemiol Infect. 2014;142(9):1934-44.

17. Schlosser J, Eiden M, Vina-Rodriguez A, Fast C, Dremsek P, Lange E, Ulrich RG Groschup MH. Natural and experimental hepatitis E virus genotype 3-infection in European wild boar is transmissible to domestic pigs. Vet Res. 2014;45:121.

18. Bouwknegt M, Rutjes SA, Reusken CB, Stockhofe-Zurwieden N, Frankena K, de Jong MC, de Roda Husman AM, Poel WH. The course of hepatitis E virus infection in pigs after contact-infection and intravenous inoculation. BMC Vet Res. 2009:5:7.

19. Galiana C, Fernandez-Barredo S, Garcia A, Gomez MT, Perez-Gracia MT. Occupational exposure to hepatitis E virus (HEV) in swine workers. Am J Trop Med Hyg. 2008;78(6):1012-5.

20. Daniel WW, Cross CL. Biostatistics: a Foundation for Analysis in the health sciences, 10th edition: a Foundation for Analysis in the health sciences: New York: Wiley Global Education; 2012.

21. Drobeniuc J, Meng J, Reuter G, Greene-Montfort T, Khudyakova N, Dimitrova Z Kamili S, Teo CG. Serologic assays specific to immunoglobulin M antibodies against hepatitis E virus: pangenotypic evaluation of performances. Clin Infect Dis. 2010;51(3):e24-7.
22. Tremeaux P, Lhomme S, Chapuy-Regaud S, Peron JM, Alric L, Kamar N Izopet J, Abravanel F. Performance of an antigen assay for diagnosing acute hepatitis E virus genotype 3 infection. J Clin Virol. 2016;79:1-5.

23. Pischke S, Schwarze-Zander C, Bremer B, Lehmann P, Wiegand SB, Gisa A, Behrendt P, Strassburg CP, Manns MP, Wedemeyer H, et al. Hepatitis E virus Seroprevalence rate in HIV-infected patients in Germany: a comparison of two commercial assays. Intervirology. 2015;58(5):283-7.

24. Izopet J, Labrique AB, Basnyat B, Dalton HR, Kmush B, Heaney CD, Nelson KE, Ahmed ZB, Zaman K, Mansuy JM, et al. Hepatitis E virus seroprevalence in three hyperendemic areas: Nepal, Bangladesh and southwest France. J Clin Virol. 2015;70:39-42.

25. Grierson S, Heaney J, Cheney T, Morgan D, Wyllie S, Powell L, Smith D, ljaz $\mathrm{S}$, Steinbach F, Choudhury B, et al. Prevalence of hepatitis E virus infection in pigs at the time of slaughter, United Kingdom, 2013. Emerg Infect Dis. 2015:21(8):1396-401.

26. Han J, Lei Y, Liu L, Liu P, Xia J, Zhang Y, Zeng H, Wang L, Wang L, Zhuang H. SPF rabbits infected with rabbit hepatitis $\mathrm{E}$ virus isolate experimentally showing the chronicity of hepatitis. PLoS One. 2014;9(6):e99861.

27. Liu J, Zhang W, Shen Q, Yang S, Huang F, Li P, Guo X, Yang Z, Cui L, Zhu J, et al. Prevalence of antibody to hepatitis $E$ virus among pet dogs in the Jiang-Zhe area of China. Scand J Infect Dis. 2009;41(4):291-5.

28. Zhao K, Liu Q, Yu R, Li Z, Li J, Zhu H, Wu X, Tan F, Wang J, Tang X. Screening of specific diagnostic peptides of swine hepatitis $E$ virus. Virol J. 2009:6:186.

\section{Submit your next manuscript to BioMed Central and we will help you at every step:}

- We accept pre-submission inquiries

- Our selector tool helps you to find the most relevant journal

- We provide round the clock customer support

- Convenient online submission

- Thorough peer review

- Inclusion in PubMed and all major indexing services

- Maximum visibility for your research

Submit your manuscript at www.biomedcentral.com/submit
) Biomed Central 